\title{
Correction to: Strategic Public Transport Design Using Autonomous Vehicles and Other New Technologies
}

\author{
Andrés Fielbaum ${ }^{1,2}$ \\ Published online: 30 August 2019 \\ (C) Springer Science+Business Media, LLC, part of Springer Nature 2019
}

\section{Correction to: International Journal of Intelligent Transport Systems Research (190)} https://doi.org/10.1007/s13177-019-00190-5

The original article contains certain errors.

The parameter for traditional vehicles should be corrected to 10.26 [US $\$ / \mathrm{h}]$. This change does not affect at all the qualitative results of the paper, but the comparisons between AV systems and the traditional one get narrower. Correct versions of Figs. 2, 3, 5 and 6 are provided below. Note that only curves related to traditional vehicles ("Trad") are modified: total savings due to AV technology are about $15 \%$ in the feeder system and about $10 \%$ in the trunk system.

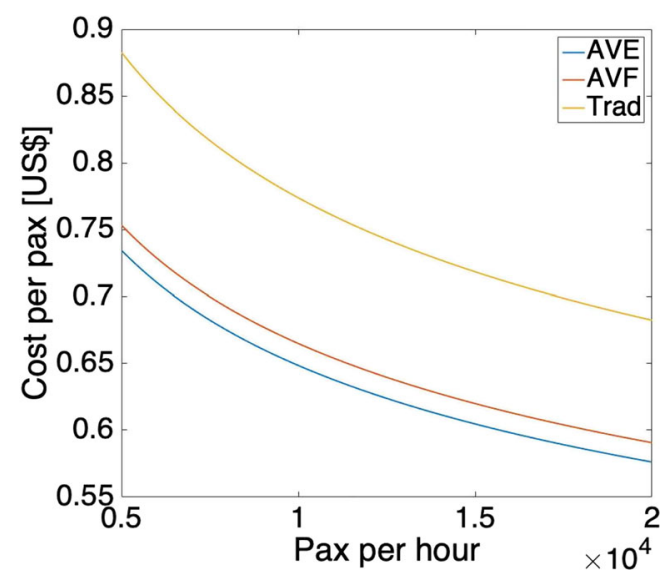

Fig. 2 Average cost per passenger for different types of vehicles in the feeder system

The online version of the original article can be found at https://doi.org/ 10.1007/s13177-019-00190-5

Andrés Fielbaum

fielbaum@gmail.com

1 Universidad de Chile, Beauchef, 851 Santiago, Chile

2 Universidad de O’Higgins, Libertador Bernardo O’Higgins, 611 Rancagua, Chile 
Fig. 3 Operational characteristics of the system for different types of vehicles
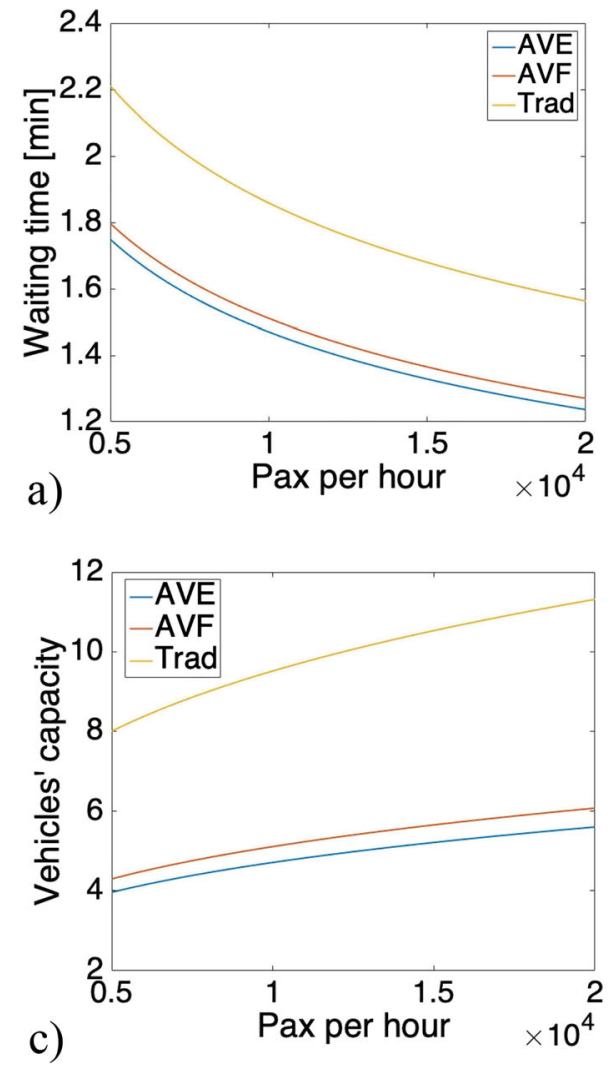
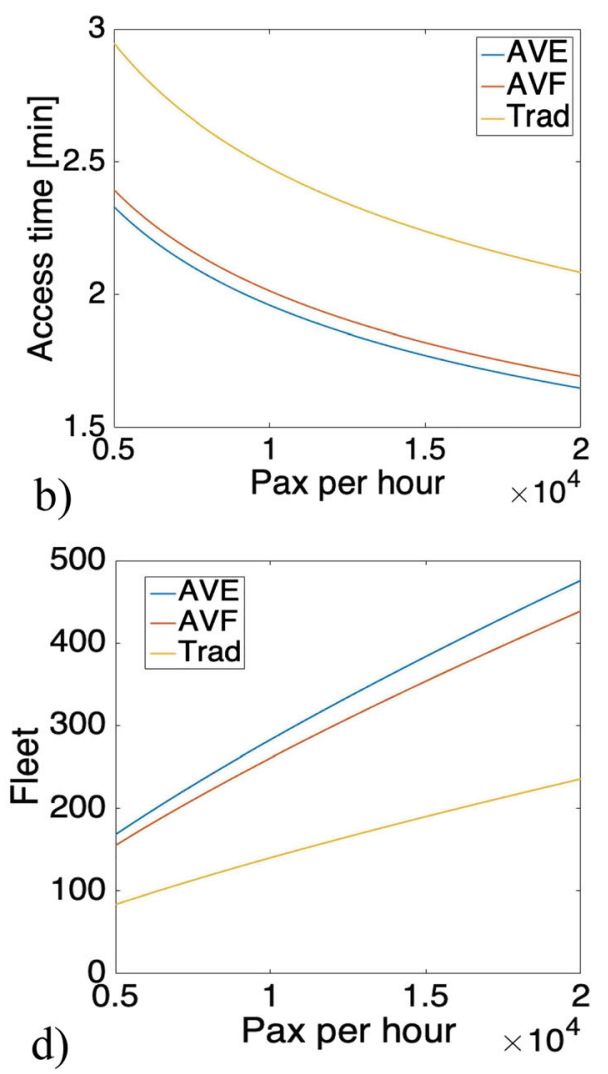

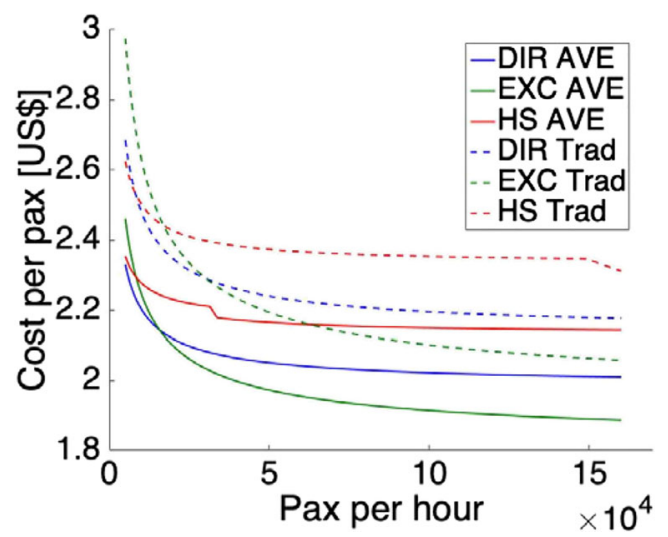

Fig. 5 Average cost per passenger for different lines structures and types of vehicles in the trunk system 
Fig. 6 Resulting average (a) operators' and (b) users' cost in the trunk system

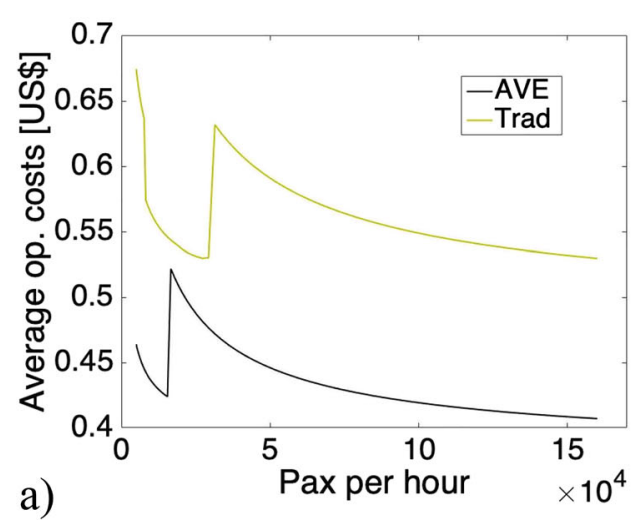

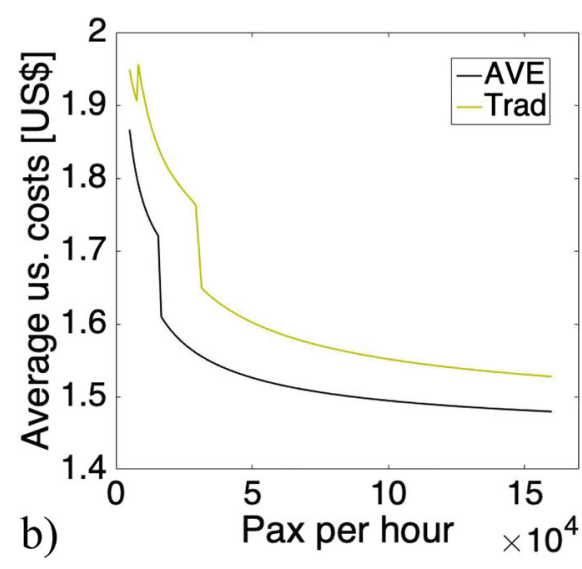

Pulisher's Note Springer Nature remains neutral with regard to jurisdictional claims in published maps and institutional affiliations 